\title{
Closing the gaps to eliminate mother-to-child transmission of HIV (MTCT) in South Africa: Understanding MTCT case rates, factors that hinder the monitoring and attainment of targets, and potential game changers
}

\author{
A Goga, ${ }^{1,2} \mathrm{PhD}$; W Chirinda, ${ }^{1} \mathrm{PhD}$; N K Ngandu, ${ }^{1} \mathrm{PhD} ; \mathrm{K}$ Ngoma, ${ }^{3} \mathrm{MSc} ; \mathrm{S}$ Bhardwaj, ${ }^{3} \mathrm{MD}$; U Feucht, ${ }^{2,4} \mathrm{PhD} ; \mathbf{N}$ Davies, ${ }^{5} \mathrm{MPH}$; \\ M Ntloana, ${ }^{6}$ Dip Nursing; O Mhlongo, ${ }^{7}$ BCur; T Silere-Maqetseba, ${ }^{6}$ BCur; F Moyo, ${ }^{8,9}$ MSc; G Sherman, ${ }^{8,9}$ PhD \\ Health Systems Research Unit, South African Medical Research Council, Cape Town, South Africa \\ ${ }^{2}$ Department of Paediatrics and Child Health, University of Pretoria, Pretoria, South Africa \\ ${ }^{3}$ Health section, UNICEF South Africa, Pretoria, South Africa \\ ${ }^{4}$ Tshwane District Health Services, Gauteng Department of Health, Pretoria, South Africa \\ "Wits Reproductive Health and HIV Institute, University of Witwatersrand, Johannesburg, South Africa \\ ${ }^{6}$ National Department of Health, Pretoria, South Africa \\ KwaZulu-Natal Department of Heath, Pietermaritzburg, South Africa \\ ${ }^{8}$ Department of Paediatrics and Child Health, Faculty of Health Sciences, University of the Witwatersrand, Johannesburg, South Africa \\ ${ }^{9}$ Centre for HIV and STI, National Institute for Communicable Diseases, Johannesburg, South Africa
}

Corresponding author: A Goga (ameena.goga@mrc.ac.za)

\begin{abstract}
Background. Ninety percent of the world's HIV-positive pregnant women live in 22 countries. These 22 countries, including South Africa (SA) have prioritised the elimination of mother-to-child transmission of HIV (EMTCT). Since 2016 all 22 countries recommend lifelong antiretroviral treatment for all HIV-positive pregnant and lactating women. To measure South African national, provincial and district-level progress towards attaining EMTCT, we analysed the number of in utero (IU) paedatric HIV infections per 100000 live births (IU case rate), and synthesised factors hindering the monitoring of EMTCT progress and attainment from the viewpoint of provincial and district-level healthcare managers and implementers. We highlight potential innovations to strengthen health systems and improve EMTCT programme delivery.

Methods. We reviewed national-, provincial- and district-level birth HIV testing data from routine National Health Laboratory Services (NHLS) records between April 2016 and March 2017. To obtain a qualitative perspective from healthcare managers and implementers, we synthesised information from the nine 2016 provincial-level EMTCT stock-taking workshops. These workshops involve key provincial and district-level staff, mentors and supporting partners. Lastly, we highlight potential innovations presented at these workshops to overcome operational challenges.

Results. The national IU mother-to-child transmission (MTCT) rate was $0.9 \%$, which translated to an IU case rate of $245 \mathrm{HIV}$-positive neonates per 100000 live births. Provincial IU percent MTCT risk ranged from $0.6 \%$ to $1.3 \%$, with IU case rates ranging between 168 and 325 cases per 100000 live births. District-level IU percent MTCT risk ranged from $0.4 \%$ to $1.9 \%$. Potential game changers include: pre-conception counselling to optimise maternal-partner health, weekly dissemination of HIV polymerase chain reaction (PCR) and viral load reports from the NHLS to specific individuals who trace mothers and infants needing care, use of ward-based outreach teams and community caregivers to trace HIV-infected mothers and their infants to link them into care, inclusion of a unique identifier in patient-held infant Road to Health booklets to facilitate infant tracing and continuous quality improvement (CQI) processes within facilities and districts and implementation of an HIV-positive baby tool to understand the characteristics and risks of HIV-positive infants. On an ecological level, provinces and districts using community-based approaches and CQI methodology seemed to have lower MTCT and IU case rates.

Conclusions. More quantitative analyses are needed to understand what proportion of the success can be attributed to community-based and CQI approaches and the impact of the potential game changers on progress towards EMTCT.
\end{abstract}

S Afr Med J 2018;108(3 Suppl 1):S17-S24. DOI:10.7196/SAMJ.2018.v108i3.12817

Ninety percent of the world's HIV-positive pregnant women live in 22 countries. These countries, including South Africa (SA), have prioritised the elimination of mother-to-child transmission of HIV (EMTCT), measured using three coverage and two impact indicators (Fig. 1). ${ }^{[1]}$ The two impact indicators are the percentage motherto-child HIV transmission (MTCT) among HIV-positive mothers (MTCT risk) and the number of new paediatric HIV infections per 100000 live births (MTCT case rate). The global target is $<5 \%$ final MTCT in breastfeeding countries and $\leq 50$ new paediatric HIV infections per 100000 live births. Consequently, to achieve EMTCT, all 22 countries currently recommend lifelong antiretroviral treatment for all HIV-positive pregnant and lactating women. This is known as PMTCT Option B+. Between the 1980s and 2015 the discovery of more effective biomedical interventions to prevent mother-to-child transmission of HIV (PMTCT) accelerated the improvement of global and national PMTCT policies; such rapid advancements in policy required flexible, responsive health systems, services and staff to assure implementation. ${ }^{[1-6]}$ For example, in 2001 the SA national 


\section{MTCT rate, as defined by WHO: \% HIV-exposed infants who acquire HIV infection from their mothers}

\section{Case rate: number of new HIV infections in children per 100000 live births}

In utero case rate: number of new HIV infections in children measured at $<7$ days of age, per 100000 live births

Fig. 1. Key concepts in the elimination of mother-to-child transmission of HIV (EMTCT).

PMTCT programme recommended single dose nevirapine (NVP) for HIV-positive pregnant women at the onset of labour and for HIV-exposed infants within 72 hours of delivery. These recommendations were made alongside modified obstetric practices and avoidance or reduced duration of breastfeeding. ${ }^{[7]}$ Between 2008 to 2013, national PMTCT improved dramatically to include the initiation of maternal antiretroviral drugs (ARVs) earlier in gestation or at higher $\mathrm{CD} 4$ cell counts. ${ }^{[8-10]}$ By January 2015, the national PMTCT policy recommended lifelong triple antiretroviral therapy (ART) for all pregnant and lactating HIV-positive women (PMTCT Option B+ policy), with infant HIV testing at birth to identify in utero infection early, expedite ART initiation and improve infant outcomes, which are poor if ART initiation is delayed. ${ }^{[11-12]}$ In 2016, SA also launched the Last Mile Plan for EMTCT. This multipronged plan acknowledges the importance of delivery systems for EMTCT and prioritises five pillars, namely: (i) leadership, governance and coordination; (ii) scaling up PMTCT coverage; (iii) integrating PMTCT interventions into routine maternal and child healthcare $(\mathrm{MCH})$ and primary healthcare (PHC); (iv) monitoring and evaluation; and $(v)$ increased community awareness and involvement. ${ }^{[13]}$ The PMTCT policy and
Last Mile Plan require implementation at all levels of the healthcare system, during the preconception, antenatal and postnatal care periods, and involve mother, father, baby and in some instances the extended family, illustrating the complexities of PMTCT programme delivery.

In a national-level review published in 2017, we demonstrate that these policy changes yielded a concomitant decrease in the national risk of early (6 weeks postpartum) MTCT, from 3.5\% in 2010 to $1.1 \%$ in $2015-16$ (Fig. 2). ${ }^{[13-16]}$ Additionally, cross-sectional surveillance data suggest that ART initiation prior to conception or during the first trimester of pregnancy could reduce early MTCT to $<1.2 \%{ }^{[14]}$ Despite these national-level successes, interprovincial and inter-district differences in MTCT and maternal ART uptake exist: the provincial in utero percent MTCT risk ranged from $1.4 \%$ to $5.9 \%$ in 2010 and $0.7-1.7 \%$ in 2015/16; maternal ART uptake ranged from $78 \%$ to $98 \%$ in $2015 / 16 .^{[14,15]}$

The district-level early MTCT rate ranged from $2.2 \%$ to $8.1 \%$ in 2010 and $0 \%$ to $3.4 \%$ in $2015 / 16$ (Fig. 2), ${ }^{[15,17,18]}$ while maternal ART uptake varied from $46 \%$ to $100 \%$ in 2015/16. ${ }^{[15]}$

We analysed the number of IU paedatric HIV infections per 100000 live births (IU case rate) as an initial step to monitor districtand provincial-level progress with EMTCT.

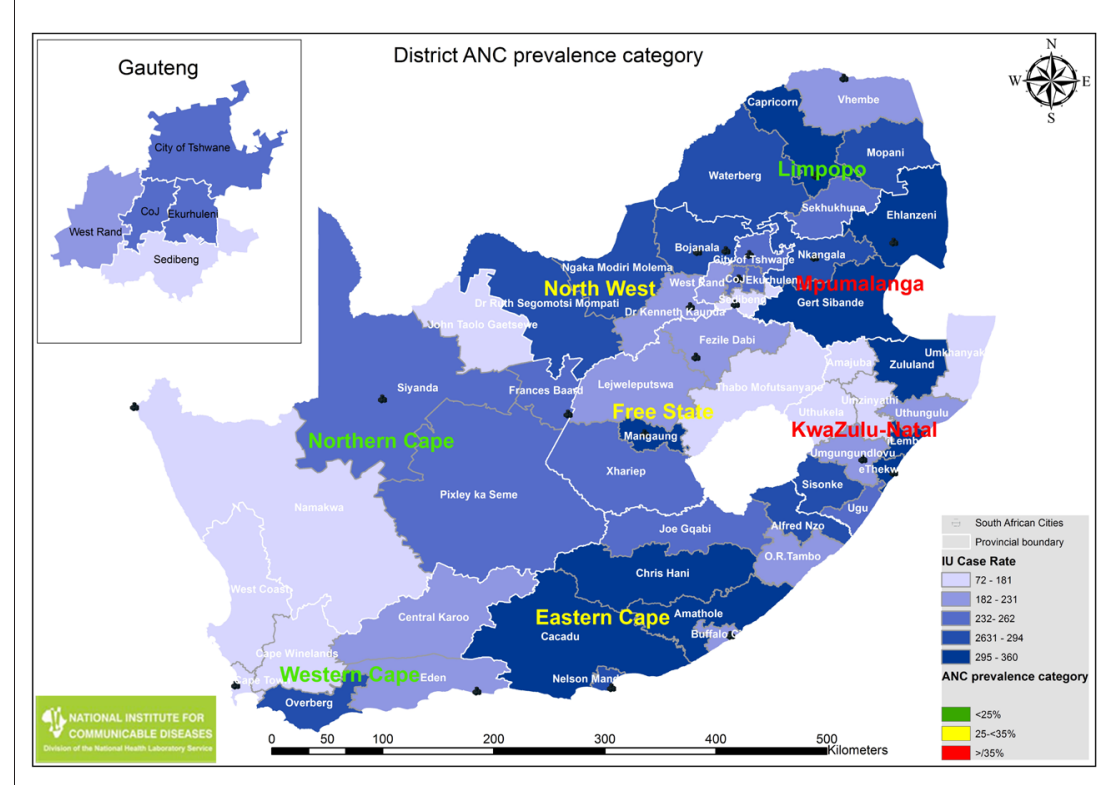

Fig. 2. Early mother-to-child transmission measured at national, provincial and district levels in South Africa.

Table 1. Definitions applied to routine NHLS data

\begin{tabular}{|c|c|c|}
\hline Definition & Numerator & Denominator \\
\hline $\begin{array}{l}\text { Birth testing coverage: Total number of HIV } \\
\text { PCR tests performed in HIV-exposed infants } \\
\text { within the first } 7 \text { days }\end{array}$ & $\begin{array}{l}\text { Total number of HIV PCR tests performed in } \\
\text { neonates aged }<7 \text { days old }\end{array}$ & $\begin{array}{l}\text { This is an estimate calculated from the DHIS } \\
\text { total live births multiplied by the antenatal } \\
\text { HIV seroprevalence rates obtained from the } \\
2013 \text { national antenatal HIV seroprevalence } \\
\text { survey }^{[30]}\end{array}$ \\
\hline $\begin{array}{l}\text { IU \% MTCT risk: \% MTCT within the first } 7 \\
\text { days of life }\end{array}$ & $\begin{array}{l}\text { Neonates within the first } 7 \text { days of life with a } \\
\text { positive HIV PCR test }\end{array}$ & $\begin{array}{l}\text { Total number of neonates tested during the } \\
\text { first } 7 \text { days of life }\end{array}$ \\
\hline $\begin{array}{l}\text { IU case rates: Number of new HIV infections } \\
\text { among- infants }<7 \text { days old expressed as a } \\
\text { standardised rate per } 100000 \text { live births }\end{array}$ & $\begin{array}{l}\text { Number of HIV PCR-positive neonates per } \\
100000 \text { live births }\end{array}$ & Total live births obtained from the DHIS \\
\hline
\end{tabular}


Additionally, we synthesised factors that hinder the monitoring of EMTCT progress and attainment, from the viewpoints of provincialand district-level healthcare managers and implementers. We have highlighted potential innovations to strengthen healthcare systems and improve EMTCT programme delivery. We include a focus on district-level, as opposed to a sole focus on national level data; inclusion of district-level data increases the granularity of our analysis.

\section{Methods}

We aimed to deepen our understanding of district- and provinciallevel progress with eliminating MTCT using mixed methods (quantitative and qualitative). Thus, we sought data that represent an entire district or province, rather than data from one single clinic or hospital.

\section{Quantitative data review}

Only two district-level sources of data are available in SA, namely the District Health Information System (DHIS) and the National Health Laboratory System (NHLS). ${ }^{[19]}$ Data from the DHIS were muddied by the fact that changes to guidelines were not accompanied by changes to DHIS indicators. There have also been concerns about the accuracy and completeness of routine DHIS data. ${ }^{[20]}$ Consequently, we analysed birth HIV testing data from the routine NHLS Corporate Data Warehouse (CDW), between April 2016 and March 2017. We focussed on NHLS data because the NHLS has protocols in place to clean and monitor data quality. We focussed on MTCT at birth for four reasons. Firstly, the SA National Department of Health (NDoH) recommends HIV testing at birth for all HIV-exposed infants. Secondly, no other data are available to determine the precise number of HIV-infected neonates. Thirdly, birth polymerase chain reaction (PCR) results are a marker of preconception and antenatal care for women. Fourthly, birth PCR results serve as an early warning sign of gaps in early infant diagnosis and PMTCT.

HIV PCR test data for HIV-exposed neonates tested before 7 days of age were extracted from the NHLS CDW. A patient-linking algorithm using deterministic matching of patient demographics (using name, surname and date of birth) and probabilistic matching was used to identify duplicates among birth HIV tests and to deal with minor mismatches created by spelling errors. Additional manual matching was performed to ensure that HIV PCR-positive neonates were not doubly counted. Programmatic outcomes namely, birth testing coverage, IU percent MTCT risk, and IU case rates were calculated at national, provincial and district level from the de-duplicated data (Table 1).

As maternal antenatal HIV sero-prevalence and number of live births influence the absolute number of IU-infected neonates, and the case rate, we separated provinces and districts into three antenatal HIV sero-prevalence categories of $<25 \%, 25-35 \%$ and $\geq 35 \%$. Within these categories, provinces with $\geq 90 \%$ and districts with $\geq 85 \%$ birth testing coverage, were ranked by case rates.

\section{Qualitative synthesis}

There are sparse published qualitative national-, provincial- or district-level data on factors affecting the monitoring of EMTCT progress and attainment, and innovative solutions to accelerate progress towards EMTCT. Consequently, to understand district-level perspectives, we reviewed reports from the provincial-level EMTCT stock-taking workshops conducted between April 2016 and March 2017. These workshops are conducted annually, are co-ordinated by the $\mathrm{NDoH}$ across all 52 districts, and are part of the institutionalised monitoring and evaluation activities outlined in the National Action

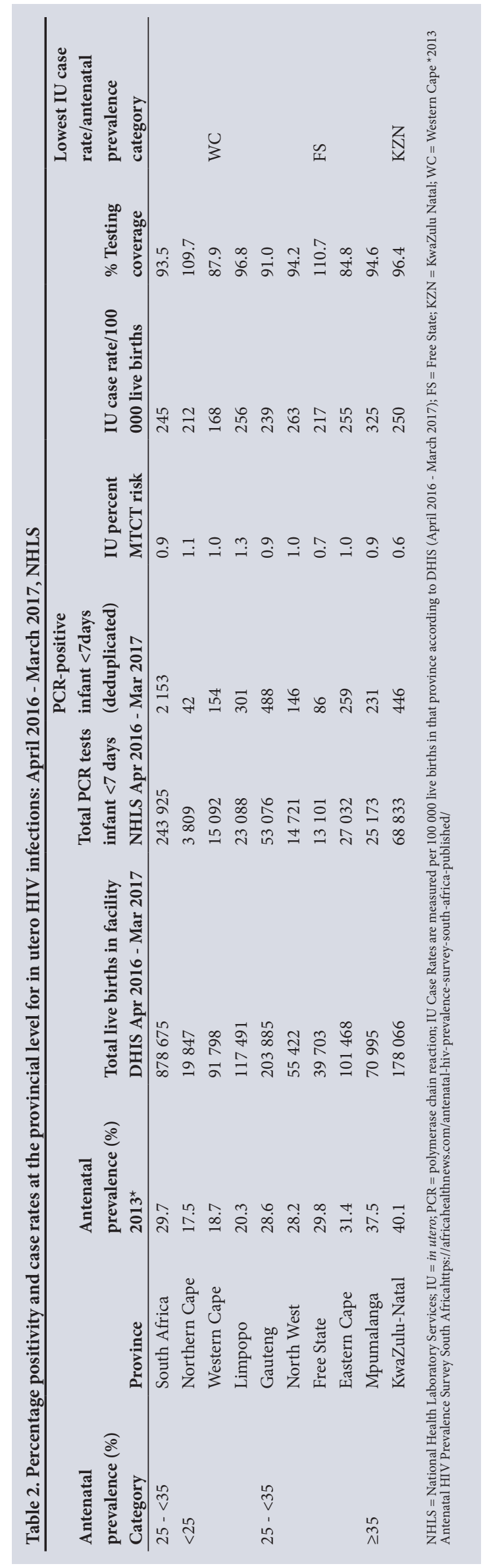


Framework, 2011 - 2015, as well as the Last Mile Plan, 2016 - 2021. ${ }^{[13]}$ The workshops provide an opportunity for districts to review district implementation plans (DIPs) and to track the achievement towards current targets. ${ }^{[21]}$ All workshop reports were systematically reviewed by one author (WC) using the following framework questions: $(i)$ what challenges are reported at provincial and district levels?; (ii) what game changers, i.e. radical innovations that fundamentally change PMTCT implementation, have been identified?:[23] and (iii) have the effects of the game changers been measured? This approach was consistent with our aims of moving away from a 'broad-brushed' national approach to understanding EMTCT progress, as well as increasing the granularity of our understanding.

\section{Results}

\section{Quantitative data review}

Birth testing coverage was $93.5 \%$ (range $85 \%-111 \%$ at provincial level); some percentages are $>100 \%$ as denominators are estimated, leading to smaller denominators than the actual. The national percentage IU percent MTCT risk was $0.9 \%$, which translated to a national IU case rate of $245 \mathrm{HIV}$-positive neonates per 100000 live births. Provincial IU percent MTCT risk ranged from $0.6 \%$ to $1.3 \%$, with IU case rates ranging from 168 to 325 cases per 100000 live births (Table 2). The Western Cape, Free State and KwaZulu-Natal had the lowest case rates within each HIV prevalence category (Table 2). District-level IU percent MTCT risk and IU case rates range from $0.4 \%$ to $1.9 \%$ and 72 to 360 , respectively (Fig. 3 and Table 3 ).

\section{Qualitative synthesis}

The 2016/17 EMTCT stock-taking workshops identified several factors that hinder EMTCT attainment, including poor internet connectivity, poor alignment between routine indicators and programmatic interventions, lack of longitudinal monitoring, poor maternal viral load monitoring and inconsistent feeding advice (Fig. 4). Despite these challenges, the workshops highlighted the following points: $(i)$ an increasingly strong focus on strengthening pre-conception, antenatal and postnatal maternal and child health services; (ii) alignment between PMTCT interventions, the last mile EMTCT plan and DIPs, to improve programme outcomes; (iii) an increased level of accountability at district and facility levels; (iv) that discussions enabled prioritisation of high MTCT districts; and $(v)$ the importance of involving different district management team members (District Clinical Specialist Teams (DCSTs), PHCand programme managers) in ongoing monitoring visits to ensure PMTCT integration into routine services. Ten potential game changers that are currently implemented to achieve fundamental healthcare system strengthening and durable improvement in the

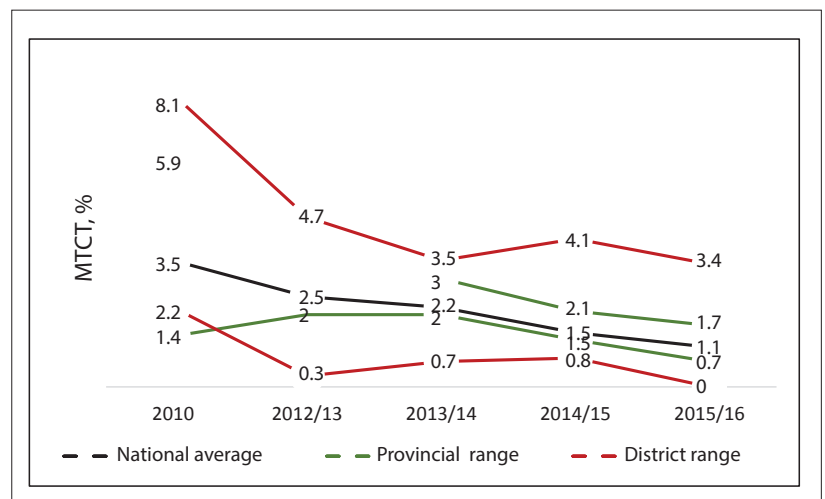

Fig. 3. Spatial distribution of IU case rates, by provincial antenatal HIV prevalence category. programme came to the fore (Fig. 4). Despite the fact that KwaZuluNatal (KZN) was the province with the second highest number of live births and had the highest antenatal HIV prevalence, its IU MTCT risk was the lowest of all provinces $(0.6 \%)$, while its IU case rate was the fifth highest (250 per 100000 live births). Ecological observations could attribute a portion of this success to the continuous quality improvement undertaken by the province: monthly teleconferences are held with district co-ordinators to review key indicators; PCR, antenatal care and postnatal care linkage forms are used to link mothers and children into care; and weekly teleconferences are held with facilities and districts to facilitate PCR monitoring. ${ }^{[23]}$

\section{Discussion}

Our quantitative analysis of birth MTCT data demonstrates varying MTCT risk and case rates by province and district, with no specific relationship between antenatal HIV prevalence, IU percent MTCT risk and case rates. The IU percent MTCT risk at birth was much

1. Poor internet connectivity and access to the weekly emails containing the NHLS Results for Action reports.

2. Poor alignment between routine indicators and PMTCT programmatic interventions. Additionally, non-reporting and inconsistent reporting yield poor quality data.

3. Lack of longitudinal cohort monitoring.

4. Poor maternal viral load monitoring.

5. Inconsistent infant feeding advice or practices.

Fig. 4. Challenges identified during the elimination of mother-to-child transmissionstock-taking workshops.

Pillar 1: Leadership, governance and co-ordination

(n) from DCSTs and other managers.

Pillar 2: Scaling up coverage of PMTCT intervention Quality improvement interventions linking mothers to community-based healthcare personnel The Mothers2Mothers 'Mother Mentor' programme, which facilitates coverage and retention in care.

Pillar 3: Integrating PMTCT into MCH Providing safe pre-conception services to couples: Two Gauteng-based services have supported $>800$ couples with preconception care. There have been no recorded vertical or horizontal HIV transmissions and early antenatal care booking rates have improved for women achieving pregnancy. Additionally, no HIV-negative women have tested HIV- positive at the time of pregnancy confirmation. A pre-printed unique identifier (ID) in each Road-to-Health Booklet (image) is being tested in the Tshwane District. This number can be used as an additional identifie on the NHLS laboratory form to facilitate continuity of care.

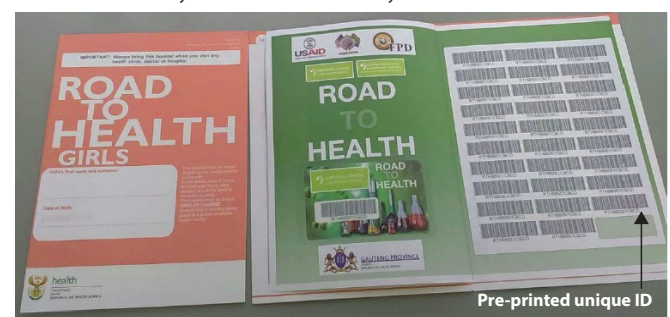

The Positive Baby Tool, which retrospectively assesses where breakdowns in the PMTCT cascade occurred, culminating in a vertical HIV transmission. This helps districts obtain a better understanding of their risk profiles.

Pillar 4: Best practices relating to monitoring and evaluation

Dashboards and cascades at facility and district levels that examine numbers as well as percentages facilitate understanding of progress and risk to health personnel within districts and identify children that require follow-up

Fig. 5. Potential game changers to strengthen health systems and programme delivery for the elimination of mother-to-child transmission of HIV. (DCSTs = district clinical specialist teams; $P M T C T=$ prevention of mother-to-child transmission of HIV; $M C H=$ maternal and child health; NHLS = National Health Laboratory Service; $P C R=$ polymerase chain reaction.) 

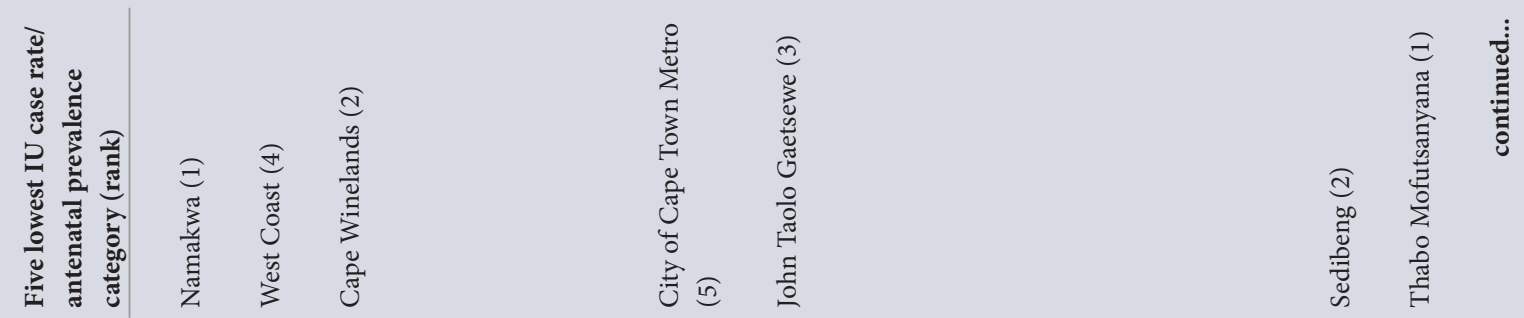

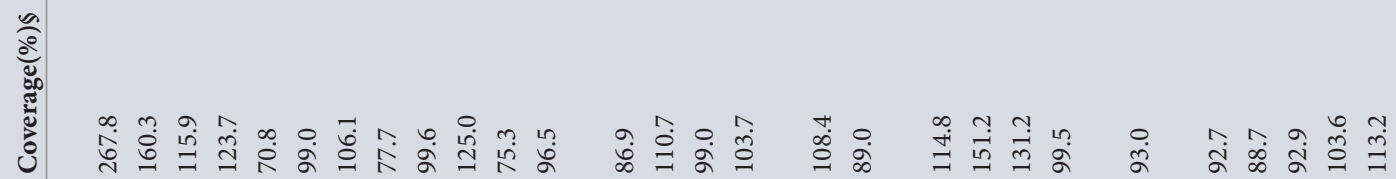

ฐั้

己ู

蒂

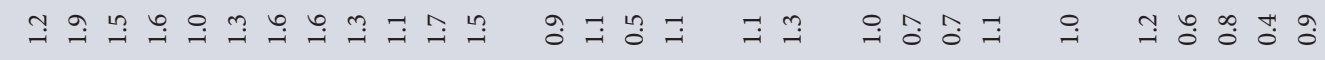

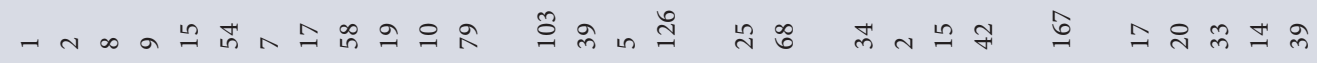

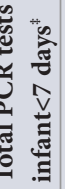

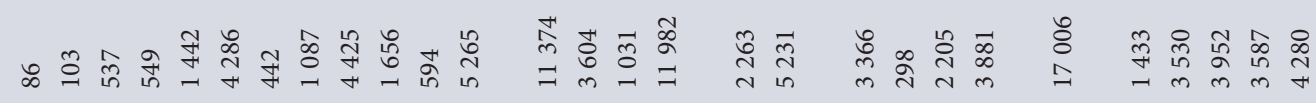

焉

भुં 品

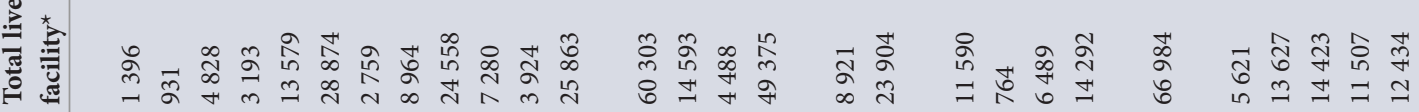

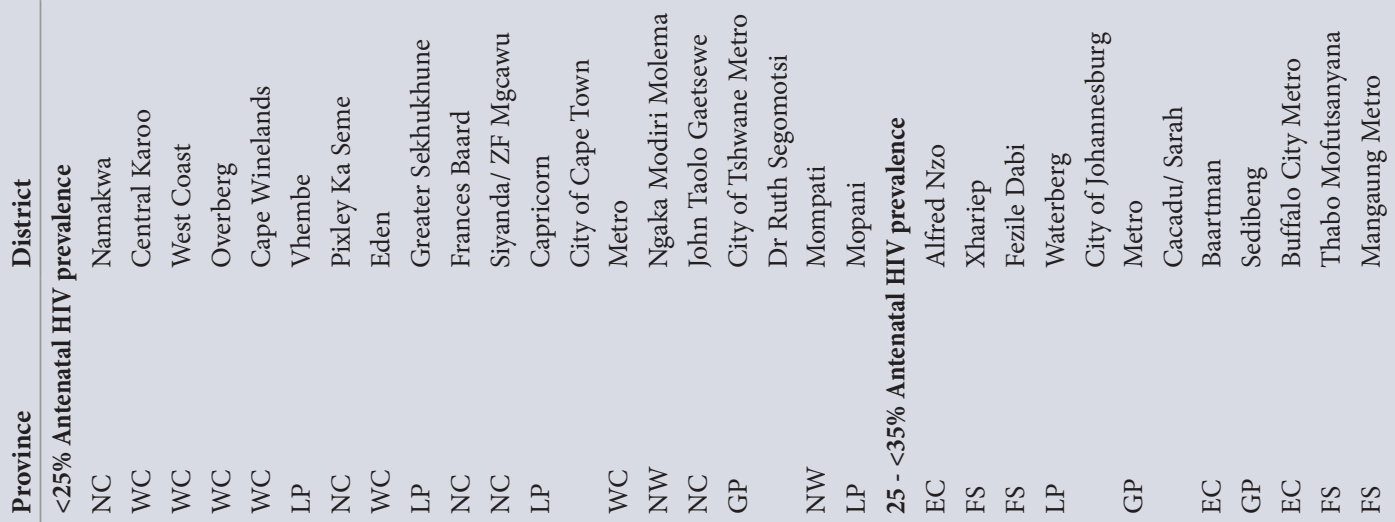




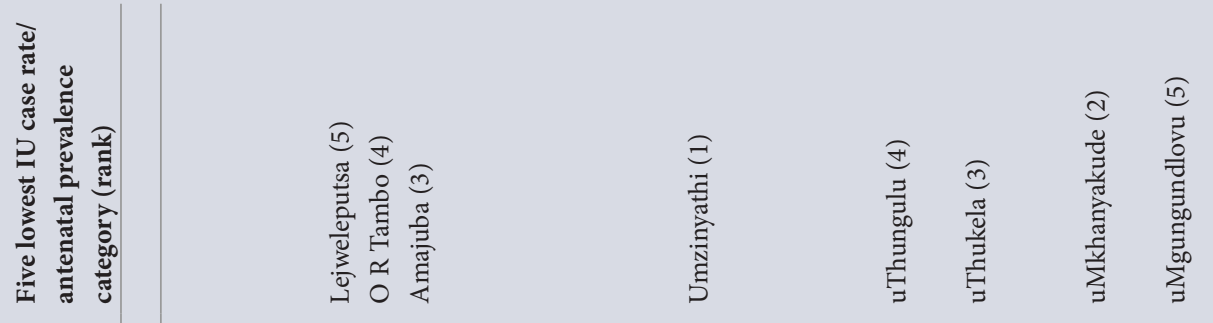

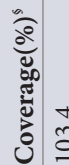

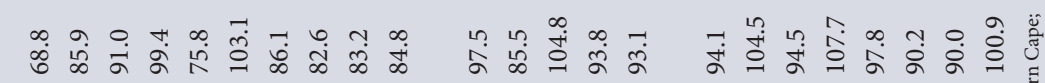

产

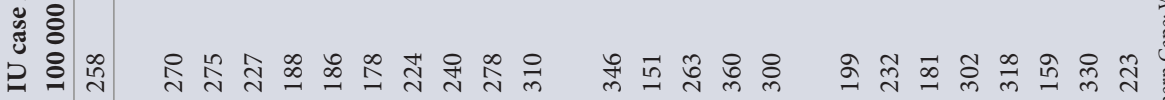

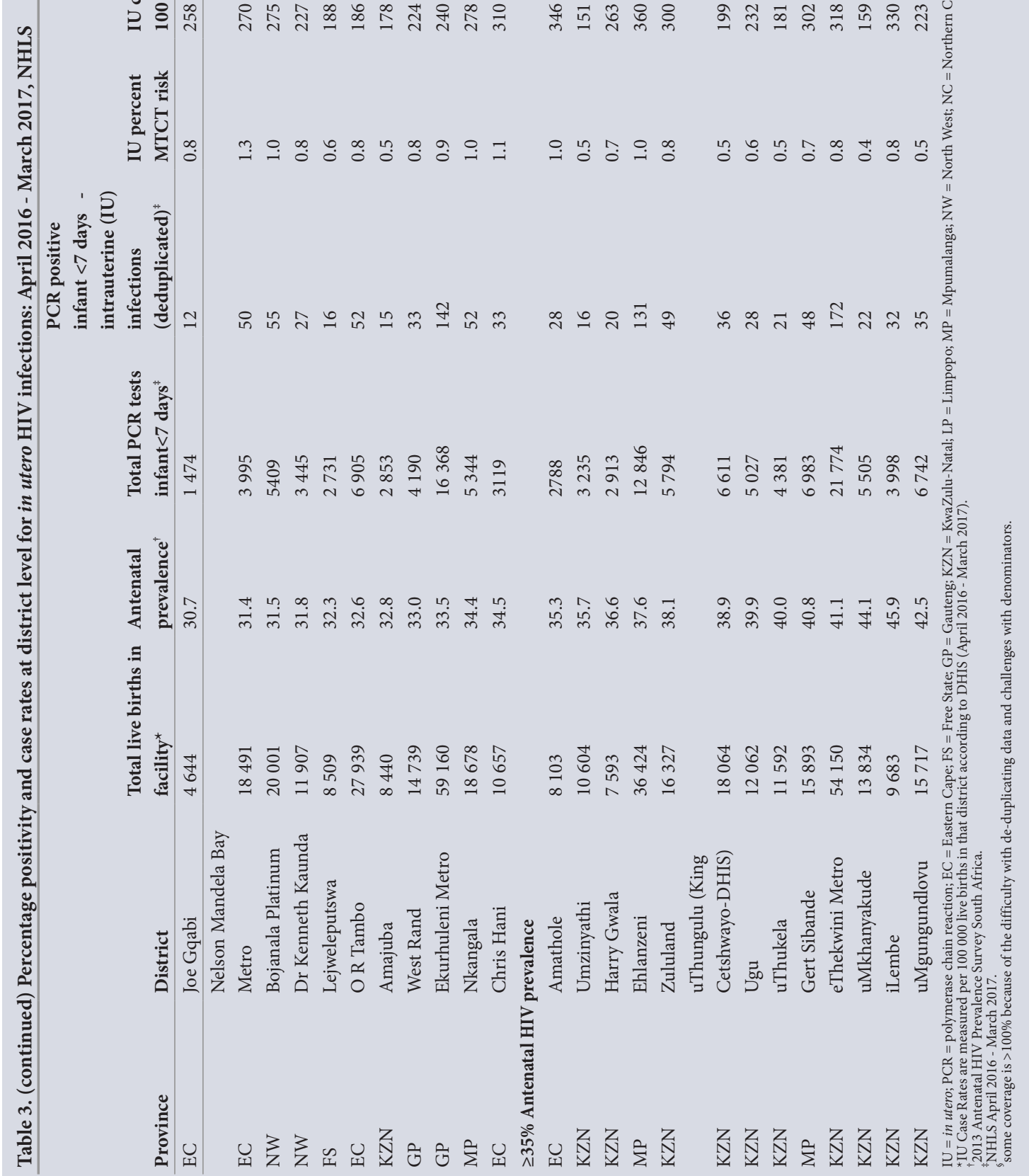


lower than the 5\% MTCT target, which demonstrates success (Fig. 1 and Tables 2 and 3), but IU case rates at the district level are up to seven-fold higher than the global target. IU case rates depend on the number of HIV-exposed infants, and thus maternal HIV prevalence. From the synthesis of district-level discussions, several game changers are currently being implemented in a non-systematic way to strengthen healthcare systems and close the gaps in EMTCT programme delivery in SA. The implementation of any game changer requires close collaboration between health facilities, laboratories, communities, healthcare staff and supporting partners as data from Uganda demonstrate that the failure to strengthen healthcare systems could be a rate-limiting step to sustainable PMTCT success. ${ }^{[24]}$ Evidence demonstrates that PMTCT programme outcomes improve after integration into the mainstream routine healthcare system for maternal and child health. ${ }^{[25]}$ Game changers should not add to the complexity of PMTCT implementation, but should strengthen routine systems to improve service delivery.

One key stumbling block to the attainment of EMTCT is poor monitoring of maternal viral suppression. Data from more experienced Option $\mathrm{B}+$ countries corroborate this key challenge. ${ }^{[26,2]]}$ In fact, a systematic review and meta-analysis in 51 countries demonstrated $73.5 \%$ overall ART adherence (defined as $>80 \%$ intake of recommended pill doses), which disaggregates into $75.7 \%$ during pregnancy and $53.3 \%$ postnatally. ${ }^{[26]}$ Being on triple antiretroviral therapy rather than prophylaxis reduced the odds of adherence. ${ }^{[26]}$ Individual-level data from 19 facilities in Malawi demonstrated that ART initiation among pregnant women with high CD4 cell counts were five times more likely to miss followup visits and women who started ART while breastfeeding were twice as likely to miss follow-up visits, compared with pregnant women needing ART for their own health. ${ }^{[27]}$ This begs the question: Why do women not adhere to their ART and follow-up visits? SA data demonstrate that conflict with work commitments, negative treatment from healthcare workers and the lack of disclosure reduce retention in care, and by deduction, adherence. ${ }^{[28]}$ HIV viral load monitoring is now even more critical following the 2016 WHO infant feeding update, which recommends exclusive breastfeeding for 6 months and continued breastfeeding for 24 months or longer for HIV-negative and HIV-positive women. ${ }^{[29]}$ Thus, strengthening healthcare systems and implementing game changers that promote retention in care and infant follow-up are urgently needed.

Ongoing monitoring and in-depth qualitative and quantitative studies are needed to identify high-burden districts and to test the impact of potential game changers on maternal and child health outcomes.

\section{Conclusion}

IU percent MTCT risk is significantly less than the 5\% final MTCT global target however, final MTCT rates at the district, provincial and national levels need to be closely monitored, as we anticipate a national increase in breastfeeding prevalence after the 2016 infant feeding update. IU case rates are considerably higher than the global target, because of high maternal HIV prevalence. We hypothesise a possible link between using community-based approaches and CQI and lower IU percent MTCT risk/IU case rates in one province (KZN) with the highest antenatal HIV prevalence. However, more in-depth studies and data are needed to understand what quality improvement methods have the greatest impact and what proportion of the success can be attributed to community-based approaches. More district-level systematic studies are needed, to quantify bottlenecks to EMTCT and to test the impact of potential game changers on the health, development, growth, and HIV-free survival of HIV-exposed infants until breastfeeding cessation, and the health of their mothers.

Acknowledgements. The development and publication of this paper was supported by the South African Medical Research Council. The NHLS provided data for the analyses. C Kajese developed the map.

Author contributions. All authors contributed equally to the conceptualisation, reviewing of drafts and approval of the final version of the manuscript. NN wrote the first draft of the introduction. WC wrote the first draft of the qualitative methods and results and undertook the analysis of EMTCT stock-taking reports. GS wrote the first draft of the quantitative methods and results, and provided data from the NHLS. FM extracted and analysed data on IU case rates and assisted with the write up. ND contributed information from the preconception strengthening intervention. UF contributed information on the unique identifiers used in the Tshwane district. OM contributed information about the interventions in KwaZulu-Natal. SB and KN provided general strategic direction for the paper. MN and TT liaised with provinces to obtain best practices and game changers. AG coordinated the writing process, combined all the contributions, synthesised the paper, and circulated drafts for comments. AG wrote the first draft of the discussion.

Funding. The South African Medical Research Council paid for the time of AG, WC and NN, and, in partnership with UNICEF, covered the cost of this publication.

Conflicts of interest. None

1. World Health Organization (WHO), Alliance for Health Policy and Systems Research. World Report on Health Systems and Health Policy Research. Geneva: WHO, 2017. http://www.who.int/allianceon Health Systems and Health Policy Research. Geneva: WHO
hpsr/news/2017/worldreport-hpsr/en/ (accessed 11 August 2017).

hpsr/news/2017/worldreport-hpsr/en/ (accessed 11 August 2017). WHO. Prevention of HIV in Infants and Young Children: Review of Evidence and WHOs
Geneva: WHO, 2002. http://www.popline.org/node/236104 (accessed 17 August 2017).

Geneva: WHO, 2002. http://www.popline.org/node/236104 (accessed 17 August 2017).
WHO. Stategic Approaches to the Prevention of HIV Infection in Children: Report of a WHO WHO. Stategic Approaches to the Prevention of HIV Infection in Children: Report of a WHO
Meeting, Morges Switzerland 20-22 March 2002. http://www.who.int/hiv/mtct/StrategicApproaches. pdf (accessed 17 August 2017).

4. WHO. Antiretroviral Drugs for Treating Pregnant Women and Preventing HIV Infection in Infants Towards Universal Access. Recommendations for a Public Health Approach. Geneva: WHO, 2006 http://www.who.int/hiv/pub/mtct/arv_guidelines_mtct.pdf (accessed 17 August 2017)

5. WHO. Antiretroviral Drugs for Treating Pregnant Women and Preventing HIV Infection in Infants Towards Universal Access. Recommendations for a Public Health Approach. Geneva: WHO, 2010 http://www.who.int/hiv/pub/mtct/arv_guidelines_mtct.pdf (accessed 17 August 2017).

6. WHO. Use of Antiretroviral Drugs for Treating Pregnant Women and Preventing HIV Infection in Inforection in Infants. Geneva: WHO,
(accessed 17 August 2017)

7. Barron P Pillay Y Doherty T, et al Fliminating mother-to-child HIV transmission in South Africa. Barron P, Pillay Y, Doherty T, et al. Eliminating mother-to-child HIV transmisior
Bull World Health Organ 2013;91:70-74. https://doi.org/10.2471/blt.12.106807

Bull World Health Organ 2013;91:70-74. https://doi.org/10.2471/blt.12.106807
8. National Department of Health (NDoH). Policy and Guidelines for the Implementation of the PMTCT National Department of Health $(\mathrm{NDoH})$. Policy and Guidelines for the Implementation of the PMTCT
programme. Pretoria: NDoH, 2008. http://www.ilo.org/wcmsp5/groups/public/---ed_protect/-protrav/---ilo_aids/documents/legaldocument/wcms_125633.pdf (accessed 17 August 2017).

9. NDoH. The South African Antiretroviral Treatment Guidelines 2013. Pretoria: NDoH, 2013. http:// www.kznhealth.gov.za/medicine/2013_art_guidelines.pdf (accessed 17 August 2017).

10. NDoH, South African National AIDS Council. Clinical Guidelines: PMTCT (Prevention of Mother to-Child Transmission). Pretoria: NDoH, 2010. http://www.fidssa.co.za/Content/Documents PMTCT_Guidelines.pdf (accessed 17 August 2017).

11. NDoH. National Conslidated Guidelines for the Prevention of Mother to Child Transmission of HIV (PMTCT) and the Management of HIV in Children, Adolescents and Adults. Pretoria: NDoH, 2015. https://www.health-e.org.za/2015/07/02/guidelines-national-consolidated-guidelines-for-pmtct-andthe-management-of-hiv-in-children-adolescents-and-adults/ (accessed 17 August 2017).

12. Violari A, Cotton M, Gibb D, et al. Early antiretroviral therapy and mortality among HIV-infected infants. N Engl J Med 2008;359:2233-2244. https://doi.org/10.1056/nejmoa0800971

13. NDoH, South Africa. The Last Mile Plan for EMTCT. Pretoria: NDoH, 2016. http://www.emtctNDoH, South Africa. The Last Mile Plan for
thelastmile.co.za/ (accessed 11 August 2017).

14. Goga A, Dinh T, Jackson D, et al. Population-level effectiveness of maternal antiretroviral treatment
thelastmile.co.za/ (accessed 11 August 2017).

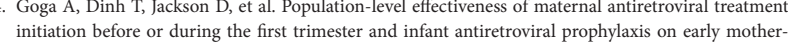
to-child transmission of HIV, South Africa: Implications for eliminating MTCT. J Glob Healt 2016;6(2):020405. https://doi.org/10.7189/jogh.06.020405

15. Massyn N, Peer N, English R. District Health Barometer 2015/6. Durban: Health Systems Trust, 2016 http://www.hst.org.za/publications/Pages/HSTDistrictHealthBarometer.aspx (accessed 17 August 2017)

16. Massyn N, Peer N, Padarath A, Barron P, Day C. District Health Barometer 2014/15. Durban Health Systems Trust, 2015. https://www.health-e.org.za/wp-content/uploads/2015/10/Complete DHB_2014_15_linked.pdf (accessed 10 August 2017).

7. Rollins N, Little K, Mzoloa S, Horwood C, Newell M-L. Surveillance of mother-to-child transmission prevention programmes at immunisation clinics: The case for universal screening. AIDS 2007;21(10):1341-1347. https://doi.org/10.1097/qad.0b013e32814db7d4

18. Sherman G, Lillian R. Early Infant Diagnosis of HIV Infection in South Africa: 2008 to 2010. http:// www.nhls.ac.za/assets/files/EID_HIV_PCR_2008-2010.pdf (accessed 17 August 2017). 
19. Goga A, Sherman G, Chirinda W, et al. Eliminating mother-to-child transmission of HIV in South

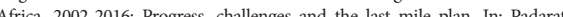
Africa, 2002-2016: Progress, challenges and the last mile plan. In: Padarath A, Barron P, edS. S Af Health Rev 2017:137-146. Anth//www.hst.org.za/publications/South\%20African\%20Health\%20 Reviews $/ 13$ _Eliminating $\% 20$ mother $\% 20$ to $\% 20$ child $\% 20$ transmission $\% 20$ of $\% 20 \mathrm{HIV} \% 20$ in $\% 20$ South $\% 20$
Africa_2002\%20to\%202016_progres__challanges $\% 20$ and $\% 20$ the $\% 20$ Last $\% 20$ Mile $\% 20$ Plan.pdf

. Nicol E, Dudley L, Bradshaw D. Assessing the quality of routine data for the prevention of motherto-child transmission of HIV: An analytical observational study in two health districts wit high HIV prevalence in South Africa. Int J Med Inform 2016;95:60-70. https://doi.org/10.1016/j. ijmedinf.2016.09.006

21. Joint United Nations Programme on HIV/AIDS (UNAIDS). 90-90-90 An ambitious treatmen target to help end the AIDS epidemic. Geneva: UNAIDS, 2014. http://www.unaids.org/en/resources/ documents/2014/90-90-90 (accessed 16 July 2017).

22. De Cock K, El-Sadr W, Ghebreyesus T. Game changers: why did the scale up on HIV treatment work despite weak health systems. J Acquir Immune Defic Syndr 2011;57(Suppl 2):S61-S63. https://doi org/10.1097/qai.0b013e3182217fo0

23. Mhlongo O. Yes we can eliminate: A case of KZN last mile approach to EMTCT. 8th South African AIDS Conference, Durban, 13 - 15 June 2017.

24. Doherty T, Besada D, Goga A, Daviaud E, Rohde S, Raphaely N. "If donors woke up tomorrow and said that we can't fund you, what would we do?" A health system dynamics analysis of implementation of PMTCT Option B+ in Uganda. Globalization Health 2017;13:51. https.//do. org/10.1186\%2Fs $12992-017-0272-2$
25. Car L, Van Velthoven M, Brusamento S, et al. Integrating prevention of mother-to-child HIV transmission programs to improve uptake: A systematic review. PLOS ONE 2012;7(4):e35268. https:// doi.org/10.1371/journal pone. 0035268

26. Nachega J, Uthman $O$, Anderson J, et al. Adherence to antiretroviral therapy during and after pregnancy in low-income, midddle-income, and high-income countries: A systematic review and meta-analysis. AIDS 2012;26(16):2039-2052. https://doi.org/10.1097/qad.0b013e328359590f

27. Tenthani L, Haas AD, Tweya $\mathrm{H}$, et al. Retention in care under universal antiretroviral therapy for HIV-infected pregnant and breastfeeding women ('Option B+') in Malawi. AIDS 2014;28(4):589-598. https://doi.org/10.1097/qad.0000000000000143

28. Clouse K, Schwartz S, Van Rie A, Bassett J, Yende N, Pettifor A. "What they wanted was to give birth; nothing else": Barriers to retention in Option B+ HIV care among postpartum women in South Africa. I Acquir Immune Defic Syndr 2014;67(1):E12-E18. https://doi.org/10.1097/qai.0000000000000263

29. African Network for Research \& Training in Sexual \& Reproductive Health \& HIV. 2016 Guideline Update on HIV and Infant Feeding. http://repronetafrica.org/2016-guideline-update-on-hiv-andinfant-feeding/ (accessed 17 August 2017)

30. NDOH. 2013 Antenatal HIV prevalence survey South Africa. Pretoria: NDoH, 2016. https://africahealthnews. com/antenatal-hiv-prevalence-survey-south-africa-published/ (accessed 17 August 2017).

Accepted 30 October 2017. 